\title{
Silver(I)-Mediated Regioselective Oxidative Cross-coupling of Phenol and Aniline Derivatives Resulting in 2'-Aminobiphenyl-2-ols
}

Sololiya C. Berkessa, ${ }^{\dagger}$ Zachary J. F. Clarke, ${ }^{\dagger}$ Jean Fotie, ${ }^{*}{ }^{\dagger}$ D. Scott Bohle, ${ }^{\dagger}$ and Casey C. Grimm. ${ }^{\S}$

†Department of Chemistry and Physics, Southeastern Louisiana University, SLU 10878, Hammond, Louisiana 70402-0878, United States

Department of Chemistry, McGill University, 801 Sherbrooke Street West, Montreal, Quebec H3A 0B8, Canada

${ }^{\S}$ Food Processing and Sensory Quality Research, United States Department of Agriculture (USDA), 1100 Robert E. Lee Boulevard, Bldg 001 SRRC, New Orleans, LA 70124, United States

\begin{abstract}
A broad and efficient regioselective aerobic oxidative cross-coupling of phenols and aniline derivatives in the presence of $\mathrm{AgNO}_{3}$ and $\mathrm{H}_{2} \mathrm{O}_{2}$ resulting in 2'-aminobiphenyl-2-ols has been developed. This reaction is selective toward the creation of a new $\mathrm{C}-\mathrm{C}$ bond at the ortho position to both amine and hydroxyl functional groups in the respective starting materials. Although oxidative cross-coupling of phenols and anilines resulting in 2'-aminobiphenyl-2-ol derivatives have been reported, these reactions have been mainly limited to 2-naphthol and 1-naphthol. This is one of the rare reports in which this type of cross-coupling reaction is expanded to simple phenol derivatives.
\end{abstract}

* Corresponding author. Tel.: +1 985549 5112; Fax: +1 985549 5126; e-mail: jean.fotie@ selu.edu 
Keywords: Dehydrogenative cross-coupling, silver(I) promoted reaction, aniline and phenol derivatives, 2'-aminobiphenyl-2-ols

\section{INTRODUCTION}

Functionalized biaryls are valuable structural motifs in numerous natural products, biologically active compounds, and in a wide range of molecules that find application as pharmaceuticals, agrochemicals and in the material industries. ${ }^{1}$ They are key components in organic conductors or semiconductors, and are efficient and selective ligands for asymmetric catalysis, especially when atropisomery is possible. ${ }^{1}$ '-Aminobiphenyl-2-ols are one of the most important subdivisions of functionalized biaryls primarily found in biologically active natural products and pharmaceuticals. ${ }^{2}$ Some examples of bioactive natural products bearing a 2'-aminobiphenyl-2-ol core moiety include ambidalmine derivatives that were shown to exhibit protective effects on hypoxic $\mathrm{H} 9 \mathrm{C} 2$ cells, ${ }^{2 \mathrm{f}}$ the cytotoxic jadomycin $^{2 c,}{ }^{2 \mathrm{~d}}$ as well as complestatin derivatives which are HIV-1 integrase inhibitors. ${ }^{2 e,}{ }^{3}$ As a result, a continuous development of highly efficient and environmentally friendly methods for synthesizing these structural units is critical in organic synthesis. Well-known reactions such as the Mizoroki-Heck and Suzuki-Miyaura have been for decades the preferred methods to access biaryls. $^{1 \text { b, } 4}$ However, in recent years, the direct arylation via $\mathrm{C}-\mathrm{H}$ activation has become a primary focus in organic synthesis mainly because these alternative methods proceed in fewer steps with a

high atom economy. ${ }^{1 c, 5}$ These new strategies have also proven to have a broader scope including the use of highly electron-rich arenes, highly electron-poor arenes as well as arenes bearing a directing group with the primary role of coordinating the transition metal catalyst and facilitating a selective $\mathrm{C}$ $\mathrm{H}$ activation. ${ }^{6}$ 
Although the dehydrogenative-homocoupling of electron-rich arenes such as aniline derivatives ${ }^{7}$ and phenols ${ }^{8}$ is very well documented, the regioselective cross-coupling of phenols and anilines resulting in 2'-aminobiphenyl-2-ol derivatives that does not involve a prefunctionalization of either of the coupling partners is much more challenging due to the potential formation of many competitive side products. Nevertheless, there are reports of the cross-dehydrogenative coupling (CDC) of either 2naphthol or 1-naphthol with aniline derivatives in the chemical literature. ${ }^{9}$ In fact, copper $^{9 \mathrm{~b}, 9 \mathrm{c}}$ and $\operatorname{iron}^{9 \mathrm{a}, 9 \mathrm{~d}}$ have been used to catalyze oxidative and regioselective cross-coupling of 2-naphthol or 1naphthol with a range of aniline derivatives resulting in the exclusive formation of a carbon-carbon bond at the ortho position to the hydroxyl and amine functional groups in the respective substrates. However, due to the difference in oxidation potentials (naphthol $=1.87 \mathrm{eV}$, phenol $=2.10 \mathrm{eV}$ ), ${ }^{8 \mathrm{~b}, 10}$ all these reactions failed when any phenol derivative other than naphthols was used as a coupling partner. ${ }^{9}$ As part of our continuous effort to investigate the effect of silver(I) in the oxidative dehydrogenative coupling of arenes resulting in the formation of $\mathrm{C}-\mathrm{N}$ bonds, ${ }^{11}$ we noticed that silver(I) can mediate the regioselective cross-coupling of phenol and aniline derivatives resulting in the exclusive formation of 2'-aminobiphenyl-2-ol derivatives, under very mild conditions. To the best of our knowledge, this is not only the first report that combines silver(I) and $\mathrm{H}_{2} \mathrm{O}_{2}$ to achieve this type of conversion, but it is also one of the rare cases where the scope of the reaction is expanded to include a wide range of phenol derivatives other than 2-naphthol and 1-naphthol. 


\section{RESULTS AND DISCUSSION}

In a previous study, we reported that silver(I) could effectively catalyzed the $\mathrm{C}-\mathrm{H} / \mathrm{N}-\mathrm{H}$ direct homocoupling of secondary arylamines resulting in the formation of a new intermolecular $\mathrm{C}-\mathrm{N}$ bond. ${ }^{11}$ In a process of expanding the scope of this reaction to include cross-couplings, we noticed that $N, N, 4$-trimethylaniline reacts with 2-naphthol in the presence of $\mathrm{Na}_{2} \mathrm{~S}_{2} \mathrm{O}_{8}$ (1 eqv) and $\mathrm{AgNO}_{3}$ (10\% mol) resulting in a regioselective formation of a carbon-carbon bond at the ortho position to the hydroxyl and amine functional groups in the respective substrates, with a very low yield (Table 1, enty1). Based on this initial observation, we decided to use both substrates for a further optimization of the reaction conditions (Table 1).

The optimization results indicated that 1 equivalent of $\mathrm{AgNO}_{3}$ was needed to drive the reaction till the complete consumption of $N, N, 4$-trimethylaniline (entries 7,11 and 19), while none of the catalytic amounts (even up to $50 \% \mathrm{~mol}$, entry 6) were able to drive the reaction to the same point. Furthermore, none of the other silver(I) salts tested $\left(\mathrm{AgCl}, \mathrm{AgOAc}\right.$ or $\left.\mathrm{AgIO}_{3}\right)$ were nearly as effective as $\mathrm{AgNO}_{3}$. This might have something to do with the low solubility of these silver salts in the solvents used. Furthermore, a number of oxidizing agents was also evaluated, and among them, $\mathrm{H}_{2} \mathrm{O}_{2}$ appeared to be the most effective under these reaction conditions, while $\left(\mathrm{NH}_{4}\right)_{2} \mathrm{~S}_{2} \mathrm{O}_{8}$ was a close second. The addition of a silver(I) salt appeared to be critical for the reaction to proceed. While $30.7 \%$ yield was observed when 1 equivalent of $\mathrm{AgNO}_{3}$ was used in the total absence of any additional oxidizing agent (entry 12), the reaction systematically failed in the total absence of silver(I), even when 3 equivalents of the oxidizing agent were present (entry 2). As far as solvents are concerned, toluene was a better solvent in many cases, and although dichloromethane appeared to produce similar yield (entry 19), it dries out throughout the reaction and had to be added, especially when the reaction is performed under open atmospheric conditions. 
Table 1. Optimization of the reaction conditions $\mathrm{s}^{\mathrm{a}}$

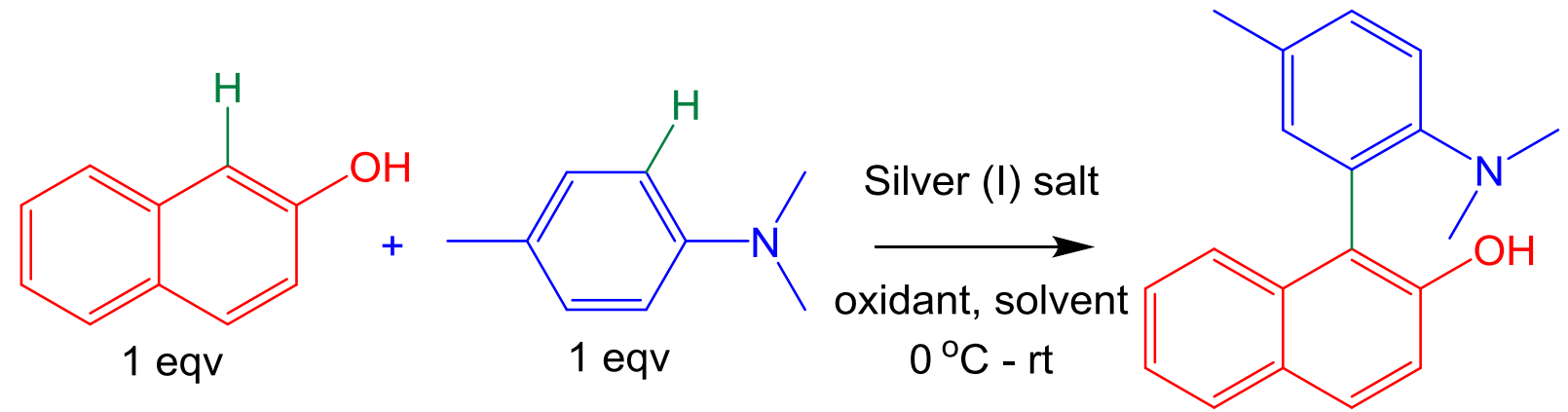

\begin{tabular}{|c|c|c|c|c|c|}
\hline Entry & Silver (eqv) & Oxidant (eqv) & Solvent & time & Yield $(\%)^{b}$ \\
\hline 1 & $\mathrm{AgNO}_{3}(0.1$ eqv $)$ & $\mathrm{Na}_{2} \mathrm{~S}_{2} \mathrm{O}_{8}$ (1 eqv) & Toluene (open air) & $6 \mathrm{~h}$ & 9.2 \\
\hline 2 & none & $\mathrm{Na}_{2} \mathrm{~S}_{2} \mathrm{O}_{8}$ (3 eqv) & Toluene (open air) & $6 \mathrm{~h}$ & $N \cdot R^{c}$ \\
\hline 3 & $\mathrm{AgNO}_{3}(1$ eqv $)$ & $\mathrm{Na}_{2} \mathrm{~S}_{2} \mathrm{O}_{8}$ (3 eqv) & Toluene (open air) & $6 \mathrm{~h}$ & 44.9 \\
\hline 4 & $\mathrm{AgNO}_{3}(0.1$ eqv $)$ & $\mathrm{H}_{2} \mathrm{O}_{2}$ (3 eqv) & Toluene (open air) & $6 \mathrm{~h}$ & 16.7 \\
\hline 5 & $\mathrm{AgNO}_{3}(0.25 \mathrm{eqv})$ & $\mathrm{H}_{2} \mathrm{O}_{2}$ (3 eqv) & Toluene (open air) & $6 \mathrm{~h}$ & 31.1 \\
\hline 6 & $\mathrm{AgNO}_{3}(0.5$ eqv $)$ & $\mathrm{H}_{2} \mathrm{O}_{2}$ (3 eqv) & Toluene (open air) & $6 \mathrm{~h}$ & 54.9 \\
\hline 7 & $\mathrm{AgNO}_{3}(1 \mathrm{eqv})$ & $\mathrm{H}_{2} \mathrm{O}_{2}$ (3 eqv) & Toluene (open air) & $6 \mathrm{~h}$ & $78.5^{d}$ \\
\hline 8 & $\mathrm{AgNO}_{3}(1$ eqv $)$ & $\mathrm{H}_{2} \mathrm{O}_{2}$ (2 eqv) & Toluene (open air) & $6 \mathrm{~h}$ & 65.7 \\
\hline 9 & $\mathrm{AgNO}_{3}$ (1 eqv) & $\mathrm{H}_{2} \mathrm{O}_{2}$ (1 eqv) & Toluene (open air) & $6 \mathrm{~h}$ & 41.2 \\
\hline 10 & $\mathrm{AgNO}_{3}$ (1 eqv) & $\mathrm{H}_{2} \mathrm{O}_{2}$ (3 eqv) & Toluene (under $\mathrm{N}_{2}$ ) & $6 \mathrm{~h}$ & 47.1 \\
\hline 11 & $\mathrm{AgNO}_{3}$ (1 eqv) & $\mathrm{H}_{2} \mathrm{O}_{2}$ (3 eqv) & Toluene (under $\mathrm{O}_{2}$ ) & $6 \mathrm{~h}$ & $75.0^{\mathrm{d}}$ \\
\hline 12 & $\mathrm{AgNO}_{3}(1$ eqv $)$ & none & Toluene (open air) & $6 \mathrm{~h}$ & 30.7 \\
\hline 13 & $\mathrm{AgIO}_{3}(1$ eqv $)$ & $\mathrm{H}_{2} \mathrm{O}_{2}$ (3 eqv) & Toluene (open air) & $6 \mathrm{~h}$ & $N \cdot R^{c}$ \\
\hline 14 & $\mathrm{AgCl}(1 \mathrm{eqv})$ & $\mathrm{H}_{2} \mathrm{O}_{2}$ (3 eqv) & Toluene (open air) & $6 \mathrm{~h}$ & $N \cdot R^{c}$ \\
\hline 15 & $\mathrm{AgOAc}(1$ eqv) & $\mathrm{H}_{2} \mathrm{O}_{2}$ (3 eqv) & Toluene (open air) & $6 \mathrm{~h}$ & traces \\
\hline 16 & $\mathrm{AgNO}_{3}(1 \mathrm{eqv})$ & $\left(\mathrm{NH}_{4}\right)_{2} \mathrm{~S}_{2} \mathrm{O}_{8}(3$ eqv $)$ & Toluene (open air) & $6 \mathrm{~h}$ & 67.8 \\
\hline 17 & $\mathrm{AgNO}_{3}$ (1 eqv) & $\mathrm{NaClO}_{4}(3$ eqv $)$ & Toluene (open air) & $6 \mathrm{~h}$ & 30.7 \\
\hline 18 & $\mathrm{AgNO}_{3}$ (1 eqv) & $\mathrm{H}_{2} \mathrm{O}_{2}(3$ eqv $)$ & THF (open air) & $6 \mathrm{~h}$ & 46.8 \\
\hline 19 & $\mathrm{AgNO}_{3}$ (1 eqv) & $\mathrm{H}_{2} \mathrm{O}_{2}$ (3 eqv) & DCM (open air) & $6 \mathrm{~h}$ & $72.3^{\mathrm{d}}$ \\
\hline 20 & $\mathrm{AgNO}_{3}(0.25$ eqv $)$ & $\mathrm{H}_{2} \mathrm{O}_{2}$ (3 eqv) & $\mathrm{DCM}$ (under $\mathrm{N}_{2}$ ) & $6 \mathrm{~h}$ & 45.3 \\
\hline 21 & $\mathrm{AgNO}_{3}(1 \mathrm{eqv})$ & $\mathrm{H}_{2} \mathrm{O}_{2}$ (3 eqv) & Dioxane (open air) & $6 \mathrm{~h}$ & 54.7 \\
\hline 22 & $\mathrm{AgNO}_{3}(1 \mathrm{eqv})$ & $\left(\mathrm{NH}_{4}\right)_{2} \mathrm{~S}_{2} \mathrm{O}_{8}(3$ eqv $)$ & THF (open air) & $6 \mathrm{~h}$ & 34.3 \\
\hline 23 & $\mathrm{AgNO}_{3}(1$ eqv $)$ & $\left(\mathrm{NH}_{4}\right)_{2} \mathrm{~S}_{2} \mathrm{O}_{8}(3$ eqv $)$ & Dioxane(open air) & $6 \mathrm{~h}$ & 62.4 \\
\hline 24 & $\mathrm{AgIO}_{3}(1$ eqv $)$ & $\left(\mathrm{NH}_{4}\right)_{2} \mathrm{~S}_{2} \mathrm{O}_{8}(3$ eqv $)$ & THF (open air) & $18 \mathrm{~h}$ & 2.7 \\
\hline 25 & $\mathrm{AgOAc}(1$ eqv $)$ & $\left(\mathrm{NH}_{4}\right)_{2} \mathrm{~S}_{2} \mathrm{O}_{8}(3$ eqv $)$ & THF (open air) & $18 \mathrm{~h}$ & 17.2 \\
\hline 26 & $\mathrm{AgIO}_{3}(1$ eqv $)$ & $\left(\mathrm{NH}_{4}\right)_{2} \mathrm{~S}_{2} \mathrm{O}_{8}(3$ eqv $)$ & Toluene(open air) & $18 \mathrm{~h}$ & 3.7 \\
\hline 27 & $\mathrm{AgOAc}(1 \mathrm{eqv})$ & $\left(\mathrm{NH}_{4}\right)_{2} \mathrm{~S}_{2} \mathrm{O}_{8}(3$ eqv $)$ & Toluene (open air) & $18 \mathrm{~h}$ & 8.8 \\
\hline 28 & $\mathrm{AgIO}_{3}(1$ eqv $)$ & $\left(\mathrm{NH}_{4}\right)_{2} \mathrm{~S}_{2} \mathrm{O}_{8}(3$ eqv $)$ & Dioxane (open air) & $18 \mathrm{~h}$ & 7.6 \\
\hline 29 & $\mathrm{AgOAc}(1$ eqv) & $\left(\mathrm{NH}_{4}\right)_{2} \mathrm{~S}_{2} \mathrm{O}_{8}(3$ eqv $)$ & Dioxane (open air) & $18 \mathrm{~h}$ & 22.2 \\
\hline
\end{tabular}

a $2.08 \mathrm{mmol}$ of $N, N, 4$-trimethylaniline was reacted with $2.08 \mathrm{mmol}$ of 2-naphthol in an ice bath. The reaction was then allowed to warm progressively to room temperature. ${ }^{\mathrm{b}}$ The yield of the reaction was determined by GC-MS using 1-bromhexadecane as an internal standard. ${ }^{\mathrm{c}}$ N.R. $=$ No Reaction. ${ }^{\mathrm{d}}$ No N,N,4-trimethylaniline was present in the mixture at the end of the reaction as indicated by GC-MS although some 2-naphthol was still present. 
The reaction also produced a better yield when run under an oxygenated environment, but the atmospheric oxygen appeared to be enough for the reaction to proceed. Based on all these observations, the reaction conditions in entry 7 ( 1 eqv $\mathrm{AgNO}_{3}$ and 3 eqv $\mathrm{H}_{2} \mathrm{O}_{2}$ in toluene under open atmospheric environment for $6 \mathrm{~h}$ ) were selected for further expansion of the scope of the reaction.

Having identified the optimal reaction conditions, the scope of the reaction was first examined by treating a series of aniline derivatives with 2-naphthol as well as with 1-naphthol, and the results are summarized in Scheme 1. Tertiary aniline derivatives with an electron-donating group such as $\mathrm{CH}_{3}$ or OEt (1a, 1b, 4, 5 and 7) at the para-position produced the envisioned products, with isolated yields between $52.6 \%$ and $70.2 \%$. However, the reaction failed when at the same position, the tertiary aniline derivative was carrying an electron-withdrawing group $\left(\mathrm{Cl}, \mathrm{Br}\right.$ or $\left.\mathrm{NO}_{2}\right)$, and even a hydrogen atom (1c-d). The reaction also failed when the tertiary aniline carries any group at the ortho to the amine, regardless of whether the group is electron-poor (2a) or electron-rich (2b). In the case of $\mathbf{2 b}$, it is obvious that steric hindrance prevents the reaction. The same steric hindrance might be responsible of the fact that aniline derivatives with two bulky groups on the amine, including two ethyl groups, failed to produce the expected products $(\mathbf{6 a - b})$. In each of these cases, the starting materials were collected. Nevertheless, the reaction appeared to tolerate aniline with one bulky group on the amine (benzyl, 4 or but-2-enyl, 5) as long as the other group is a methyl group, and providing that the aniline derivative is also carrying the much needed electron-rich group at the para-position. The reaction failed to produce any product when secondary aniline derivatives were used (even with electron-rich group at the para position 3a), and the starting materials were collected in each of these cases. On the other hand, primary anilines were quickly oxidized into the the corresponding azobenzene derivatives, and the reaction thus failed to produced the expected products. The structure of $\mathbf{1 b}$ and $\mathbf{7}$ were unambiguously confirmed by single crystal X-ray diffraction, and the molecular structures with ellipsoid representation at 50\% probability level are shown in Scheme 1. 
Scheme 1. Survey of the scope the reaction using 2-naphthol and 1-naphthol ${ }^{\mathrm{a}}$<smiles>[R]c1cc([R])c(N([R])[R10])c([14CH2])c1</smiles>
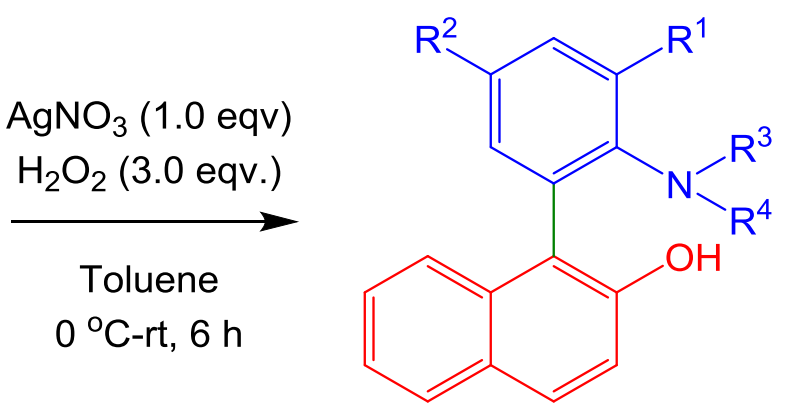<smiles>[R]c1ccc(N(C)C)c(-c2c(O)ccc3ccccc23)c1</smiles>

1a: $\mathrm{R}^{2}=\mathrm{CH}_{3}(65.3 \%)$

1b: $R^{2}=$ OEt $(70.2 \%)$

1c: $\mathrm{R}^{2}=\mathrm{Cl}, \mathrm{Br}$ or $\mathrm{NO}_{2}(\mathrm{~N} . \mathrm{R})^{\mathrm{b}}$

1d: $R^{2}=H(N \cdot R)^{b}$

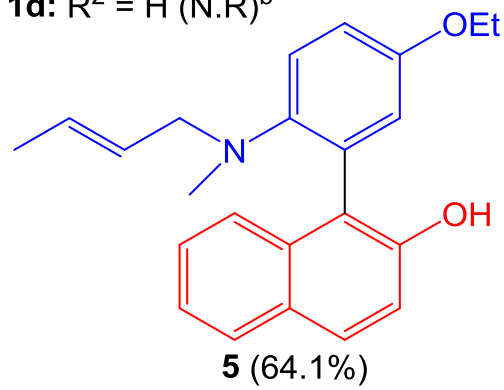<smiles>[R]c1cccc(-c2c(O)ccc3ccccc23)c1N(C)C</smiles>

2a: $R^{1}=B r(N \cdot R)^{b}$ 2b: $R^{1}=$ OMe $(N \cdot R)^{b}$<smiles>[R]c1cc([R])c(NC)c(-c2c(O)ccc3ccccc23)c1</smiles>

3a: $R^{1}=H, R^{2}=$ OEt $(N \cdot R)^{b}$ 3b: $R^{1}=O E t, R^{2}=H(N . R)^{b}$<smiles></smiles><smiles>[R1]N([R])c1ccc(OCC)cc1-c1c(O)ccc2ccccc12</smiles>

6a: $\mathrm{R}^{3}=\mathrm{R}^{4}=\mathrm{CH}_{2} \mathrm{CH}_{3}(\mathrm{~N} . \mathrm{R})^{\mathrm{b}}$

6b: $\mathrm{R}^{3}=\mathrm{R}^{4}=\mathrm{CH}_{2} \mathrm{Ph}(\mathrm{N} \cdot \mathrm{R})^{\mathrm{b}}$<smiles>Cc1ccc(N(C)C)c(-c2ccc3ccccc3c2O)c1</smiles>

$7^{\mathrm{c}}(52.6 \%)$
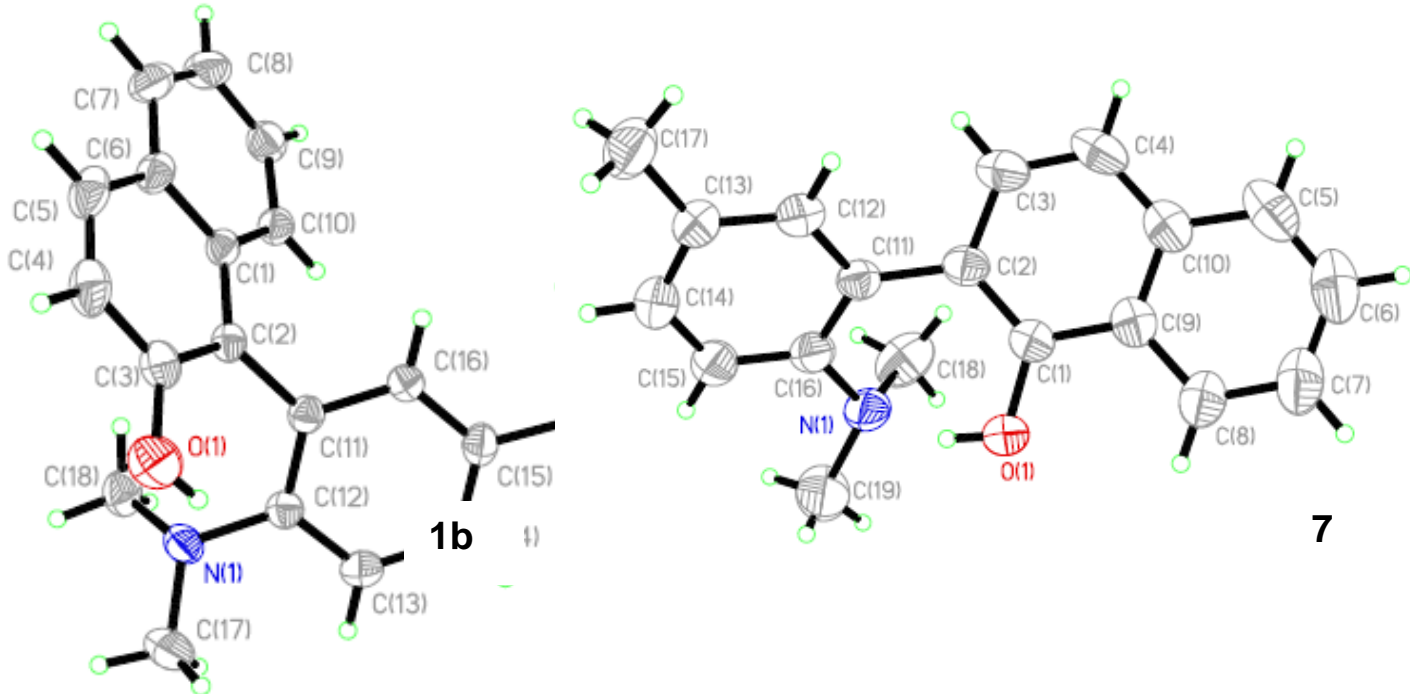
${ }^{\mathrm{a}}$ These are all isolated yields; ${ }^{\mathrm{b}}$ N.R = No Reaction (as indicated by GC-MS analysis), ${ }^{\mathrm{c}}$ For compound 7, 1naphthol was used as a substitute for 2-naphthol. The single crystal X-ray data for 1b (CCDC 1442427) and 7 (CCDC 1442428) are deposited in the Cambridge database, and copies of these materials can be obtained free of charge from CCDC, 12 Union Road, Cambridge CB2 1EZ, UK, http://www.ccdc.am.ac.uk.

Because these types of cross-dehydrogenative couplings with either 2-naphthol or 1-naphthol have already been achieved under different reaction conditions, and considering the fact that all these reactions failed when simple phenols (other naphthols) were used as a coupling partner, ${ }^{9}$ the primary focus was directed toward simple phenol derivatives. Scheme 2 summarizes the results obtained when treating a series of $N, N$-dimethylaniline derivatives with different types of substituted phenols. Simple phenols appeared to follow the same reactivity trend observed with 2-naphthol. In fact, 4ethoxy- $N, N$-dimethylaniline reacted with phenol as well as with a wide range of para-substituted phenols to produce the corresponding 2'-aminobiphenyl-2-ol derivatives (8a-f). The isolated yield for these reactions ranges from $52.3 \%$ for 4 -isopropylphenol to $69.8 \%$ for 4 -methylphenol. The electronrich or electron-poor nature of the groups at the para-position of theses phenols does not seem to have any significant impact on the reactivity of these coupling partners since 4-bromophenol (59.2\%) and 4-chlorophenol (60.3\%) produced a yield similar to that found for 4-methoxyphenol $(56.7 \%)$ or 4-isopropylphenol (52.3\%).

To examine whether having substituents at different position of the phenol ring will have any effect on its reactivity, 3-chlorophenol, 3,4-dichlorophenol, 3,4-dimethylphenol and 2-methoxyphenol were reacted with 4-ethoxy- $N, N$-dimethylaniline. Among these reactants, only 2-methoxyphenol failed to produce the expected product $(\mathbf{9 d})$. This result indicates that any group at the ortho-position of either coupling partners (phenols or aniline derivatives) will create enough steric hindrance to preclude the reaction from proceeding. On the other hand, 3-chlorophenol, 3,4-dichlorophenol and 3,4dimethylphenol produced the expected product, with a very similar yield 9a (57.6\%), 9b (53.8\%) and 9c $(59.4 \%)$, respectively. However, the reaction does not tolerate reactive functional groups such as nitro, nitriles and esters as the reaction systematically failed to produce the expected products when 3- 
or 4-nitrophenol, methyl 3-hydroxybenzoate, methyl 4-hydroxybenzoate and 4-hydroxybenzonitrile were used as starting materials. 4-Hydroxyacetophenone produced only traces of the expected product as indicated by GC-MS analysis. In each of these cases, the post-reaction mixtures appeared to contain a significant amount of 4-ethoxy- $N, N$-dimethylaniline used as the coupling partner, while the phenol derivative was fully (or almost fully) consumed. The side products obtained from these latter reactions have not yet been fully characterized.

Scheme 2. Survey of the scope of the reaction using different types of substituted phenols ${ }^{\mathrm{a}}$

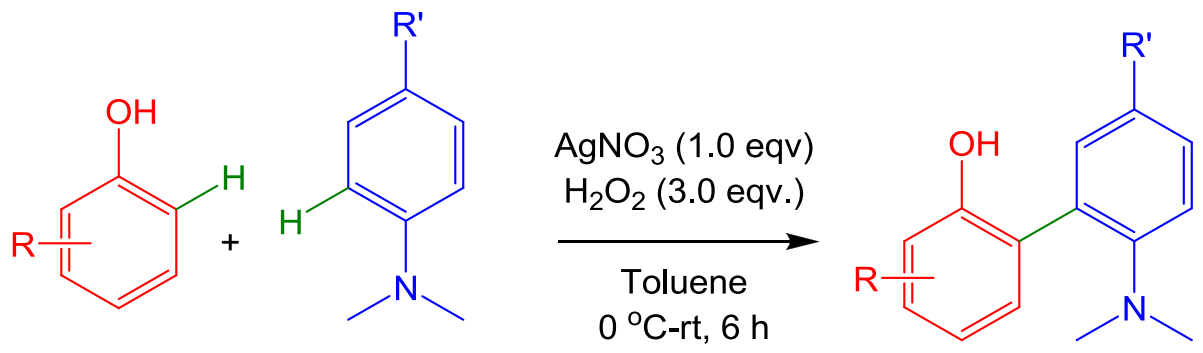

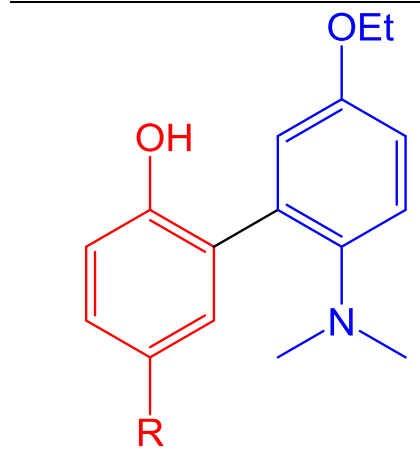

8a: $R=H(65.7 \%)$

8b: $R=B r(59.2 \%)$

8c: $\mathrm{R}=\mathrm{Cl}(60.3 \%)$

8d: $\mathrm{R}=\mathrm{CH}_{3}(69.8 \%)$

8e: $\mathrm{R}=\mathrm{OMe}(56.7 \%)$

8f: $R=i-\operatorname{Pr}(52.3 \%)$

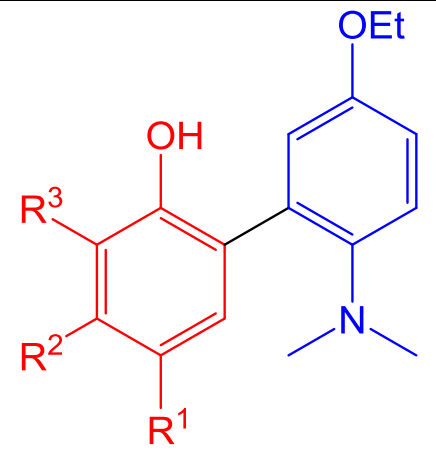

9a: $\mathrm{R}^{1}=\mathrm{H}, \mathrm{R}^{2}=\mathrm{Cl}, \mathrm{R}^{3}=\mathrm{H}(57.6 \%)$

9b: $R^{1}=R^{2}=\mathrm{Cl}, \mathrm{R}^{3}=\mathrm{H}(53.8 \%)$

9c: $\mathrm{R}^{1}=\mathrm{R}^{2}=\mathrm{CH}_{3}, \mathrm{R}^{3}=\mathrm{H}(59.4 \%)$

9d: $R^{1}=R^{2}=H, R^{3}=$ OMe $(N . R)^{b}$

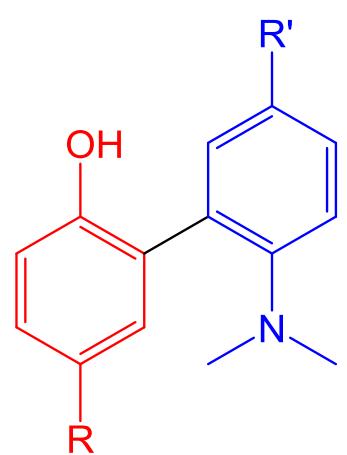

10a: $R=H, R^{\prime}=H(N . R)^{b}$

10b: $R=H, R^{\prime}=B r(N \cdot R)^{b}$

10c: $R=O M e, R^{\prime}=H(N . R)^{b}$

10d: $R=B r, R^{\prime}=H(N . R)^{b}$

a These are all isolated yields; ${ }^{b}$ N.R = No Reaction as indicated by GC-MS analysis

Furthermore, to investigate the electronic effect of electron-rich or electron-poor substituents on the aniline coupling partner, $N, N$-dimethylaniline, $N, N, 4$-trimethylaniline, 4-bromo- $N, N$-dimethylaniline were treated with phenol, 4-methoxyphenol and 4-bromophenol, respectively. As expected, the 
electronic nature of the substituents appeared to have little effect on the reactivity of phenols. However, they seem to determine the reactivity of the aniline coupling partners. Any aniline derivative with either a hydrogen or an electron-withdrawing group (10a-d) failed to produce any product regardless of the phenol coupling partner, and the starting material was collected in each of these cases. This indicates that under these conditions, the reaction requires that the aniline derivative carries a strong electron donating group.

The effect of the size of the groups attached to the nitrogen of the aniline coupling partner (steric hindrance) was also investigated (see Scheme 3). It turned out that, unlike 2-naphthol that could not tolerate more than two ethyl groups on the nitrogen of the aniline (6a), phenols appeared to react easily with 4-ethoxy- $N, N$-diethylaniline to produce the expected products in acceptable yields as illustrated by 11a (47.3\%) and 11b (45.8\%).

Scheme 3: Survey of the steric effects of groups attached to the nitrogen of the aniline on the reaction $^{\mathrm{a}}$<smiles>[R]c1ccc(O)c([CH2+])c1</smiles>

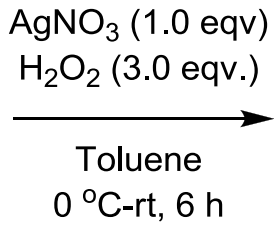<smiles>[R]c1ccc(O)c(-c2cc(OCC)ccc2N([R])[R])c1</smiles> 


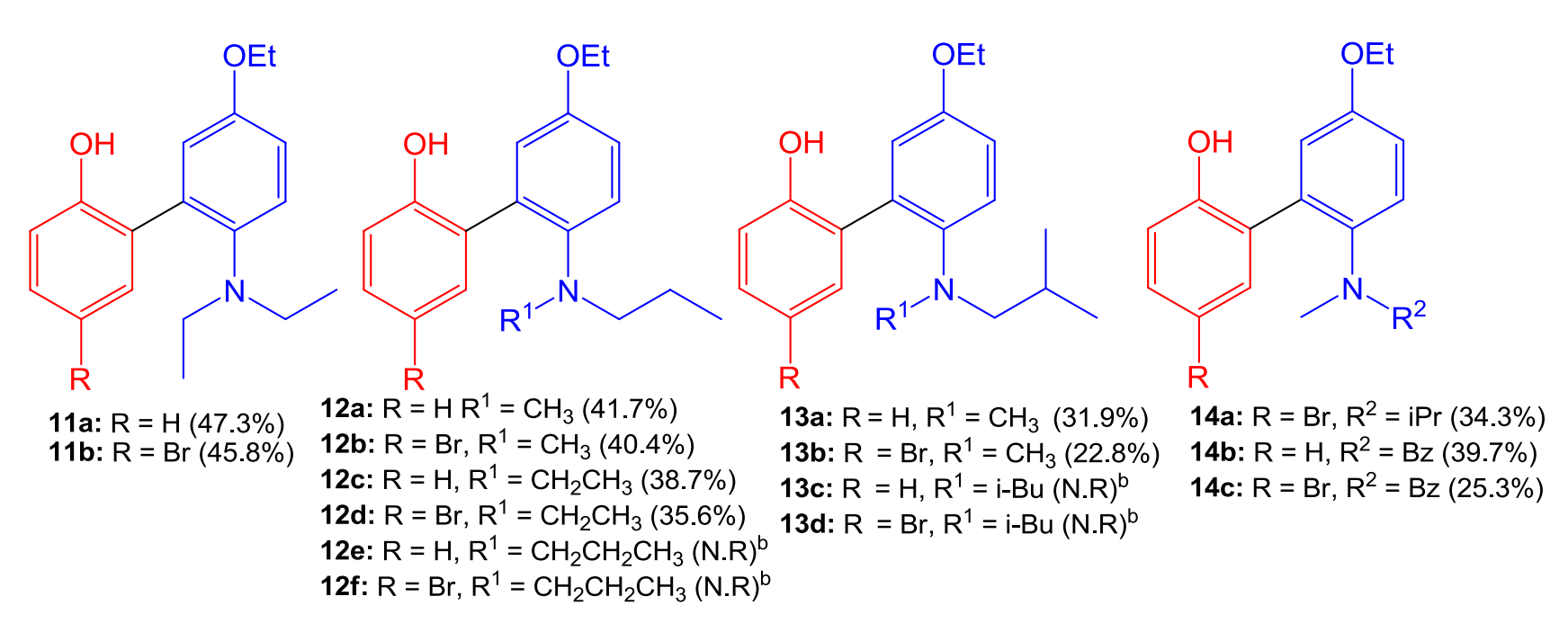

${ }^{a}$ These are all isolated yields; ${ }^{b}$ N.R = No Reaction as indicated by GC-MS analysis

However, they appeared not to be able to tolerate two substituents with more than 2 carbon-chains on the nitrogen of the aniline as indicated by $12 \mathrm{e}-\mathbf{f}$ and $13 \mathbf{c}-\mathbf{d}$. Nevertheless, the reaction tolerates one bulky groups including propyl, isopropyl, isobutyl and even benzyl on the nitrogen of the aniline, as long as the other group is a methyl or an ethyl (see 12a-c, 13a-b, 14a-c). However, the yield of the reaction appeared to be significantly affected by the bulkiness of these groups. For example, $\mathbf{8 b}$ obtained by reacting 4-bromophenol with 4-ethoxy- $N, N$-dimethylaniline produced $59.2 \%$ yield, while reacting the same 4-bromophenol with 4-ethoxy- $N, N$-diethylaniline, 4-ethoxy- $N$-methyl- $N$ propylaniline, 4-ethoxy- $N$-ethyl- $N$-propylaniline, 4-ethoxy- $N$-isobutyl- $N$-methylaniline or $N$-benzyl4-ethoxy- $N$-methylaniline produced only $47.3 \%(\mathbf{1 1 b}), 45.8 \%(\mathbf{1 2 b}), 35.6 \%(\mathbf{1 2 d}), 22.8 \%(\mathbf{1 3 b})$ and $25.3 \%$ (14c), respectively. Since electron-rich groups on the aniline coupling partner seem to be having a beneficial effect on the reaction, we thought that adding more electro-donating groups on aniline will result in the improvement of the yield of the reaction. To examine this hypothesis, 3,4dimethoxy- $N, N$-dimethylaniline was reacted with 4-bromophenol, phenol and 3-chlorophenol, respectively (see Scheme 4). 
Scheme 4: Survey of the reactivity of 3,4-dimethoxy- $N, N$-dimethylaniline towards 4-bromophenol, phenol and 3-chlorophenol, respectively ${ }^{\mathrm{a}}$
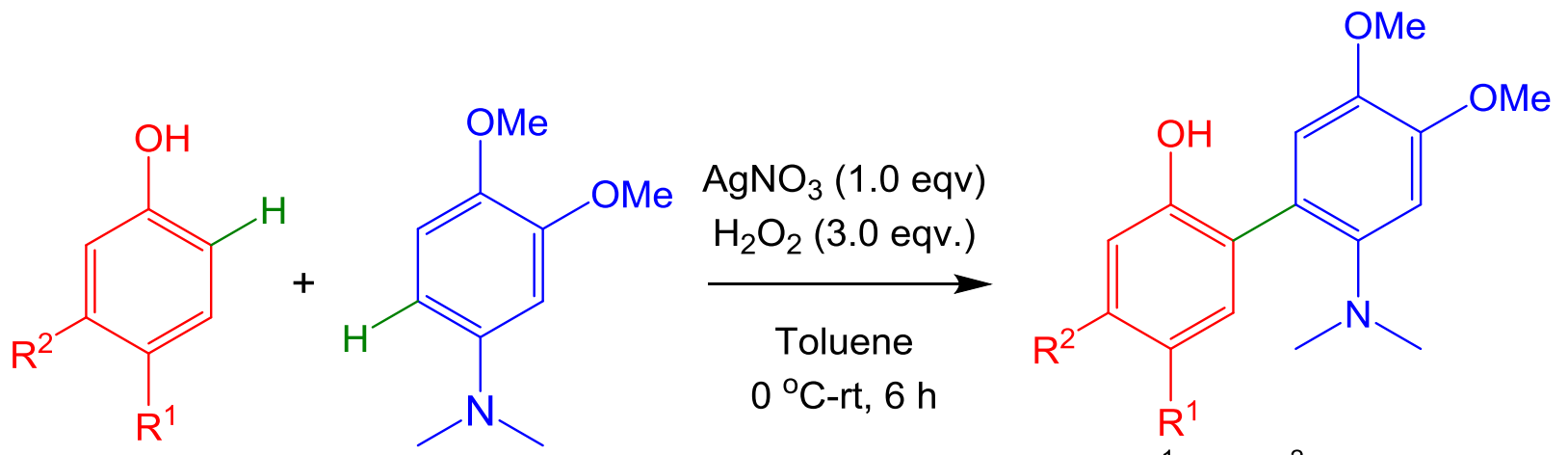

15a: $R^{1}=B r, R^{2}=H(12.5 \%)$

15b: $R^{1}=R^{2}=H$ (traces) $^{b}$

15c: $\mathrm{R}^{1}=\mathrm{H}, \mathrm{R}^{2}=\mathrm{Cl}$ (traces) ${ }^{\mathrm{b}}$

a These are all isolated yields; ${ }^{\mathrm{b}}$ Traces are as indicated by the GC-MS analysis.

Suprizingly, the yields of these reactions dropped dramatically, with only the reaction with 4bromophenol (15a, 12.5\%) producing enough product for a full characterization while the two other reactions produced only traces of the product as indicated by the GC-MS analyses. In this case, it is probable that 3,4-dimethoxy-N,N-dimethylaniline $(0.44 \mathrm{eV})$ is oxidizing at a much faster rate than other aniline derivatrives, and thus follows a path that leads mainly to a side-product rather than to the expected product.

A considerable number of investigations towards elucidating the mechanism of crossdehydrogenative coupling of phenols as well as explaning the observed chemoselectivity are reported in the chemical litterature. In fact, while explaining the chemoselectivity observed during a $\mathrm{Cu}(\mathrm{II})-$ catalyzed naphthol/naphthylamine cross-dehydrogenative coupling, Hovorka and Zavada suggested that the formation of a binuclear $\mathrm{Cu}(\mathrm{II}) /$ amine complex comprising metal centers with different redox potentials was responsible for the observed selectivity. ${ }^{12}$ The same approach was used by Chandrasekharam et $a l,{ }^{9 a}$ to explain the selectivity observed in their iron(III)-catalyzed crossdehydrogenative coupling of aniline derivatives and naphthols. However, based on electrochemical measurements and frontier molecular orbital theory, Kočovský and coworkers suggested that many of 
these reactions involves the coupling between an electrophilic radical and an anionic acceptor, and that cross-coupling is favored when the difference in redox potentials between the two coupling partners is at least $0.25 \mathrm{~V} .^{9 b, 13}$ In this case, the coupling partner with the lowest redox potential is selectively oxidized into an electrophilic radical, while the other one plays the role of the nucleophile. Following a similar approach in our case, one would expect the aniline derivatives, based on their lower redox potentials when compared to that of the phenol coupling partners, to be oxidized into the electrophilic radical, leaving the phenols to assume the role of nucleophiles. If this was the case, electronwithdrawing groups on the aniline derivatives will have a stabilizing effect on the electrophilic radical and thus improve the yield of the reaction. Instead, electronwithdrawing groups on the aniline derivatives appeared to preclude the reaction from proceeding, and concomitantly, the electronic effects of substituents on the phenol coupling partners seem to have little to no effect. These observations suggest that phenols, rather than the aniline derivatives, are oxidized into the electrophilic radical intermediate, and the electron-donating groups on the aniline coupling partners improve their nucleophilicity, resulting in the observed improved yield for the reaction. As a result, we propose the following tentative mechanism for the silver(I)-mediated cross-coupling reaction. The reaction starts with the formation of a silver(I)-phenol complex followed by one electron oxidation resulting in a electrophilic radical intermediate (A). Subsequently, a nucleophilic attack by the aniline derivative on the electrophilic radical intermediate (A) results in the formation of intermediate $\mathrm{B}$ through the creation of a new $\mathrm{C}-\mathrm{C}$ bond. Finally, the dehydroaromatization of intermediate $\mathrm{B}$ produces the product as illustrated in Scheme 5. It should be mentioned that a quantitative amount of metallic silver is produced during the course of the reaction.

These observation are consistent with the recent report by Libman et al, ${ }^{14}$ that showed the critical importance of the phenol-metal binding during the oxidation step of the reaction that can result in the selective oxidation of the most available functional group, even if this latter has a much higher 
oxidation potential. ${ }^{14}$ In our case, since the nitrogen atom is fully substituted (tertiary amine), the correspondent aniline derivatives are less suceptible to a coordination with silver(I), and as result, the formation of a phenol-silver complex leading to the selective oxidation of the phenols into the electrophilic radical intermediate (A) is favored. This might explain why the electronic effect of substituents on the phenol coupling partners has little effect on the reaction. This also explains why secondary aniline derivative failed to produce any product through this reaction, as they can easily form a strong complex with silver(I) through a coordination reaction. The formation of such a complex destroys any nucleophilic tendency for the nitrogen atom involved, and as a result, the reaction will not proceed, even in a case of the formation of an electrophilic phenol radical intermediate.

Scheme 5: Tentative mechanistic pathway for the cross-dehydrogenative coupling reaction between phenols and aniline derivatives
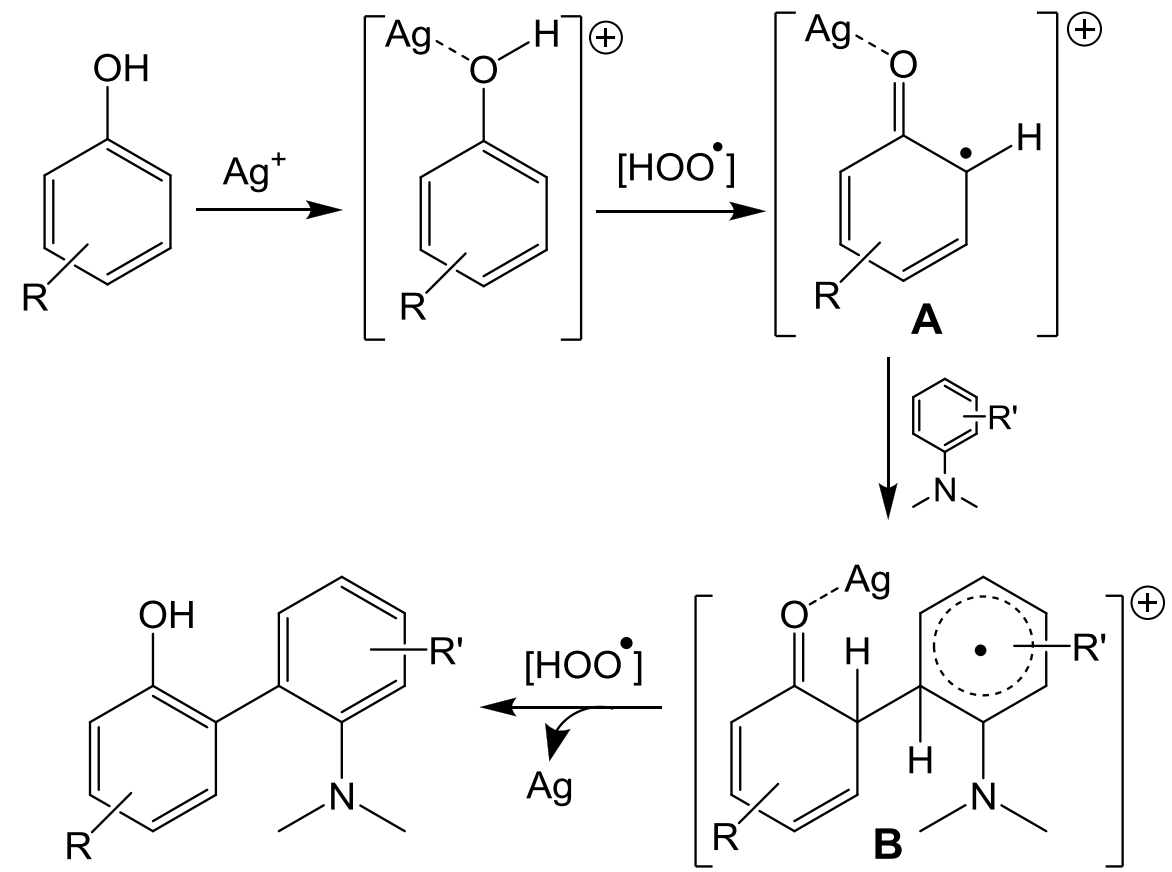
It is also important to mention that attempts at coupling anisole derivatives with 4-ethoxy- $N, N$ dimethylaniline failed to produce the expected product, and the starting material was collected at the end of the reaction. This is an indication of the critical importance of a free hydroxyl group for this reaction. However, since aniline derivatives are fully consumed while leftover phenols are consistantly found in the mixture at the end of each reaction, it is conceivable that these aniline derivatives are also competitively oxidized under these conditions, and that the resulting intermediates take a different reaction path leading to the quick consumption of the aniline coupling partner. All these observations are consistent with the tentative reaction mechanism shown in Scheme 5. Further investigations are currently ongoing in our lab to fully ellucidate the mechanism of this reaction, and will be reported in due course.

\section{CONCLUSION}

A broad-spectrum and regioselective oxidative cross-dehydrogenative coupling reaction between phenols and aniline derivatives has been developed. This reaction is promoted by $\mathrm{AgNO}_{3}$ in the presence of $\mathrm{H}_{2} \mathrm{O}_{2}$ under mild conditions. The reaction takes place under an opened atmospheric environment indicating that it is not sensitive to either oxygen or moisture in the air. This reaction is selective toward the creation of a new $\mathrm{C}-\mathrm{C}$ bond at the ortho position of both amine and hydroxyl functional groups in the respective starting materials. Furthermore, although oxidative cross-coupling of phenols and anilines resulting in 2'-aminobiphenyl-2-ol derivatives have been previously reported, these reactions have been mainly limited to 2-naphthol and 1-naphthol. This is one of the rare reports in which the scope of this type of cross-coupling reaction is expanded to include simple phenol derivatives. 


\section{ACKNOWLEDGMENTS}

JF acknowledges support from the National Science Foundation under grant \# MRI-1337372, and the Louisiana Board of Regents Support Fund: Supervised Undergraduate Research Experiences (LEQSF-EPS(2015)-SURE-152). D.S.B. gratefully acknowledges support from NSERC and the CRC.

\section{REFERENCES}

1. (a) Hassan, J.; Sevignon, M.; Gozzi, C.; Schulz, E.; Lemaire, M. Chem. Rev. 2002, 102, 1359. (b) Nicolaou, K. C.; Bulger, P. G.; Sarlah, D. Angew. Chem., Int. Ed. 2005, 44, 4442. (c) McGlacken, G. P.; Bateman, L. M. Chem. Soc. Rev. 2009, 38, 2447.

2. (a) Martinez-Farina, C. F.; Jakeman, D. L. Chem. Commun. 2015, 51, 14617. (b) Martinez-Farina, C. F.; Robertson, A. W.; Yin, H.; Monro, S.; McFarland, S. A.; Syvitski, R. T.; Jakeman, D. L. J. Nat. Prod. 2015, 78, 1208. (c) Fan, K.; Zhang, X.; Liu, H.; Han, H.; Luo, Y.; Wang, Q.; Geng, M.; Yang, K. J. Antibiot. 2012, 65, 449. (d) Zheng, J.-T.; Rix, U.; Zhao, L.; Mattingly, C.; Adams, V.; Chen, Q.; Rohr, J.; Yang, K.-Q. J. Antibiot. 2005, 58, 405. (e) Singh, S. B.; Jayasuriya, H.; Salituro, G. M.; Zink, D. L.; Shafiee, A.; Heimbuch, B.; Silverman, K. C.; Lingham, R. B.; Genilloud, O.; Teran, A.; Vilella, D.; Felock, P.; Hazuda, D. J. Nat. Prod. 2001, 64, 874. (f) Yang, Z.; Liu, Z.; Jiang, B.; Teng, F.; Wang, Y.; Han, N.; Guo, D.; Yin, J. Eur. J. Med. Chem. 2014, 84, 417. (g) Reyes, F.; Fernandez, R.; Rodriguez, A.; Bueno, S.; de Eguilior, C.; Francesch, A.; Cuevas, C. J. Nat. Prod. 2008, 71, 1046. 
3. (a) Singh, S. B. In Discovery and development of natural product inhibitors of HIV-1 integrase, John Wiley \& Sons, Inc., 2011; pp 309-323. (b) Singh, S. B.; Jayasuriya, H.; Hazuda, D. L.; Felock, P.; Homnick, C. F.; Sardana, M.; Patane, M. A. Tetrahedron Lett. 1998, 39, 8769.

4. (a) Asefa, T.; Biradar, A. V.; Das, S.; Sharma, K. K.; Silva, R. In Nanocatalysts for the Heck coupling reactions, John Wiley \& Sons, Inc., 2013; pp 11-50. (b) Basle, O. RSC Green Chem. Ser. 2015, 26, 197. (c) Bolm, C. J. Org. Chem. 2012, 77, 5221. (d) Braese, S.; de Meijere, A. In Crosscoupling of organyl halides with alkenes - the Heck reaction, Wiley-VCH Verlag GmbH \& Co. KGaA, 2014; pp 533-663. (e) Dhakshinamoorthy, A.; Asiri, A. M.; Garcia, H. Chem. Soc. Rev. 2015 , 44, 1922. (f) Felpin, F.-X. Synlett 2014, 25, 1055. (g) Phan, N. T. S.; Van Der Sluys, M.; Jones, C. W. Adv. Synth. Catal. 2006, 348, 609. (h) Zafar, M. N.; Mohsin, M. A.; Danish, M.; Nazar, M. F.; Murtaza, S. Russ. J. Coord. Chem. 2014, 40, 781.

5. (a) Musaev, D. G.; Figg, T. M.; Kaledin, A. L. Chem. Soc. Rev. 2014, 43, 5009. (b) Roopan, S. M.; Palaniraja, J. Res. Chem. Intermed. 2014, 41, 8111. (c) Shibahara, F.; Murai, T. Asian J. Org. Chem. 2013, 2, 624. (d) You, S.-L.; Xia, J.-B. Top. Curr. Chem. 2010, 292, 165. (e) Ricci, P.; Kramer, K.; Cambeiro, X. C.; Larrosa, I. J. Am. Chem. Soc. 2013, 135, 13258.

6. (a) Bunescu, A.; Piou, T.; Wang, Q.; Zhu, J. Org. Lett. 2015, 17, 334. (b) Jeon, W. H.; Lee, T. S.; Kim, E. J.; Moon, B.; Kang, J. Tetrahedron 2013, 69, 5152. (c) Lian, Z.; Friis, S. D.; Skrydstrup, T. Chem. Commun. 2015, 51, 1870. (d) Rong, Y.; Li, R.; Lu, W. Organometallics 2007, 26, 4376. (e) Sun, Q.; Zhang, C.; Kong, H.; Tan, Q.; Xu, W. Chem. Commun. 2014, 50, 11825. (f) Wang, D.; Izawa, Y.; Stahl, S. S. J. Am. Chem. Soc. 2014, 136, 9914. 
7. (a) Kirchgessner, M.; Sreenath, K.; Gopidas, K. R. J. Org. Chem. 2006, 71, 9849. (b) Vyskocil, S.;

Smrcina, M.; Lorenc, M.; Tislerova, I.; Brooks, R. D.; Kulagowski, J. J.; Langer, V.; Farrugia, L. J.; Kocovsky, P. J. Org. Chem. 2001, 66, 1359-1365.

8. (a) Esguerra, K. V. N.; Fall, Y.; Petitjean, L.; Lumb, J.-P. J. Am. Chem. Soc. 2014, 136, 7662. (b) Lee, Y. E.; Cao, T.; Torruellas, C.; Kozlowski, M. C. J. Am. Chem. Soc. 2014, 136, 6782. (c) Kirste, A.; Elsler, B.; Schnakenburg, G.; Waldvogel, S. R. J. Am. Chem. Soc. 2012, 134, 3571. (d) More, N. Y.; Jeganmohan, M. Org. Lett. 2015, 17, 3042.

9. (a) Chandrasekharam, M.; Chiranjeevi, B.; Gupta, K. S. V.; Sridhar, B. J. Org. Chem. 2011, 76, 10229. (b) Smrcina, M.; Lorenc, M.; Hanus, V.; Sedmera, P.; Kocovsky, P. J. Org. Chem. 1992, 57, 1917. (c) Vyskocil, S.; Smrcina, M.; Lorenc, M.; Hanus, V.; Polasek, M.; Kocovsky, P. Chem. Commun. 1998, (5), 585. (d) Ding, K.; Xu, Q.; Wang, Y.; Liu, J.; Yu, Z.; Du, B.; Wu, Y.; Koshima, H.; Matsuura, T. Chem. Commun. 1997, (7), 693.

10. Bordwell, F. G.; Cheng, J. J. Am. Chem. Soc. 1991, 113, 1736-43.

11. Fotie, J.; Rhodus, J. L.; Taha, H. A.; Reid, C. S. Heteroat. Chem. 2012, 23, 598.

12. Hovorka, M.; Zavada, J. Tetrahedron 1992, 48, 9517.

13. (a) Kocovsky, P.; Vyskocil, S.; Smrcina, M. Chem. Rev. 2003, 103, 3213. (b) Smrcina, M.; Vyskocil, S.; Maca, B.; Polasek, M.; Claxton, T. A.; Abbott, A. P.; Kocovsky, P. J. Org. Chem. 1994, 59, 2156-63.

14. Libman, A.; Shalit, H.; Vainer, Y.; Narute, S.; Kozuch, S.; Pappo, D. J. Am. Chem. Soc. 2015, $137,11453$. 


\section{Graphical Abstract}

Silver(I)-Mediated Regioselective Oxidative
Cross-coupling of Phenol and Aniline Derivatives
Resulting in 2'-Aminobiphenyl-2-ols
Sololiya $\mathrm{C}$. Berkessa, ${ }^{\dagger}$ Zachary J. F. Clarke, ${ }^{\dagger}$ Jean Fotie, ${ }^{\prime \dagger}{ }^{\dagger} \mathrm{D}$. Scott Bohle, ${ }^{\dagger}$ and Casey C. Grimm. ${ }^{\S}$

